EPJ Web of Conferences 106, 05010 (2016)

DOI: $10.1051 /$ epjconf/201610605010

(C) Owned by the authors, published by EDP Sciences, 2016

\title{
Validation of MCNP NPP Activation Simulations for Decommissioning Studies by Analysis of NPP Neutron Activation Foil Measurement Campaigns
}

\author{
Ben Volmert ${ }^{1}$, Manuel Pantelias ${ }^{1}$, R.K. Mutnuru ${ }^{2}$, Erwin Neukaeter ${ }^{3}$, and Beat Bitterli ${ }^{4}$ \\ ${ }^{1}$ National Cooperative for the Disposal of Radioactive Waste (Nagra), 5430 Wettingen, Switzerland \\ ${ }^{2}$ NRG, Westerduinweg 3, 1755LE Petten, The Netherlands \\ ${ }^{3}$ BKW FMB Energie AG-Kernkraftwerk Muehleberg, 3203 Muehleberg, Switzerland \\ ${ }^{4}$ Kernkraftwerk Goesgen-Daeniken AG, 4658 Daeniken, Switzerland
}

\begin{abstract}
In this paper, an overview of the Swiss Nuclear Power Plant (NPP) activation methodology is presented and the work towards its validation by in-situ NPP foil irradiation campaigns is outlined. Nuclear Research and consultancy Group (NRG) in The Netherlands has been given the task of performing the corresponding neutron metrology. For this purpose, small Aluminium boxes containing a set of circular-shaped neutron activation foils have been prepared. After being irradiated for one complete reactor cycle, the sets have been successfully retrieved, followed by gamma-spectrometric measurements of the individual foils at NRG. Along with the individual activities of the foils, the reaction rates and thermal, intermediate and fast neutron fluence rates at the foil locations have been determined. These determinations include appropriate corrections for gamma self-absorption and neutron selfshielding as well as corresponding measurement uncertainties. The comparison of the NPP Monte Carlo calculations with the results of the foil measurements is done by using an individual generic MCNP model functioning as an interface and allowing the simulation of individual foil activation by predetermined neutron spectra. To summarize, the comparison between calculation and measurement serve as a sound validation of the Swiss NPP activation methodology by demonstrating a satisfying agreement between measurement and calculation. Finally, the validation offers a chance for further improvements of the existing NPP models by ensuing calibration and/or modelling optimizations for key components and structures.
\end{abstract}

\section{Introduction}

Future NPP decommissioning is in the spotlight worldwide - the more so after some countries (e.g. Germany and Switzerland) decided to phase out of nuclear energy after the events in Fukushima.

In Switzerland, existing law specifies the "polluter pays principle", meaning that the nuclear energy utilities must cover waste management costs fully by themselves. In order to update the cost estimate for the Decommissioning Fund, decommissioning studies have to be performed on a regular basis for each Swiss NPP. One important step in the decommissioning study is the determination of the radiological inventory of an NPP resulting from its lifetime operation. Knowledge of the total radiological inventory

This is an Open Access article distributed under the terms of the Creative Commons Attribution License 2.0, which permits unrestricted use, distribution, and reproduction in any medium, provided the original work is properly cited. 


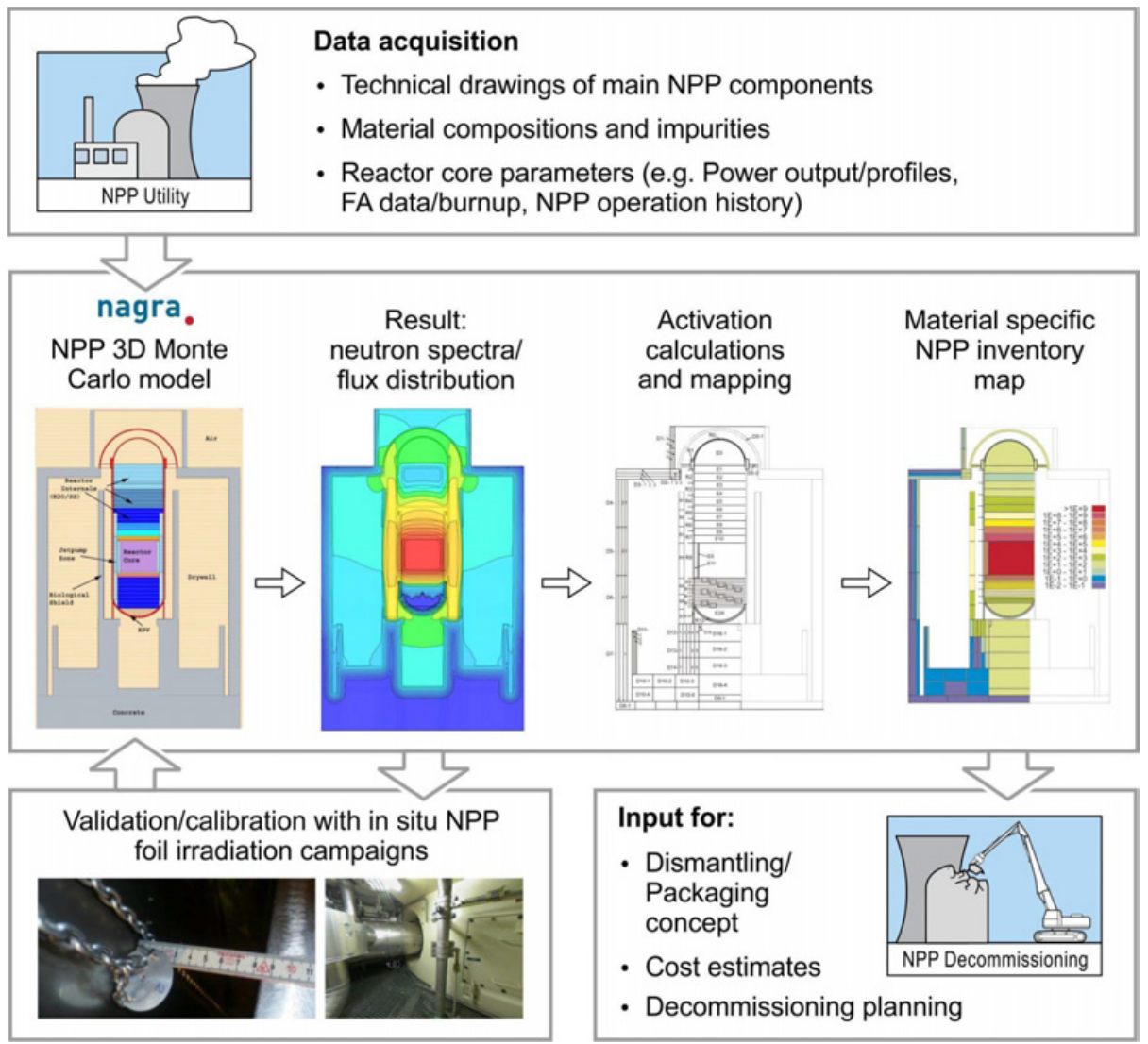

Figure 1. Scheme of the Nagra methodology for the NPP activation analysis for decommission planning.

and its distribution within the reactor building is essential for developing the entire operational sequence of the decommissioning work as well as the waste packaging concept.

In this paper, an overview of the Nagra NPP activation methodology is presented and the work towards its validation by in-situ NPP foil irradiation campaigns is outlined. The result for the first successful validation of the methodology is presented and discussed.

\section{Methodology of the Nagra NPP Activation Analysis}

In Fig. 1 the Nagra methodology for NPP activation analysis is outlined. The first step consists of collecting all required data from the NPP. This data collection step is supported by visits to the plant, taking pictures and measurements of key components or dimensions, and intensive research in the archives to collect as much required information as possible. NPP core data and operational history are used up to a certain level of detail being sufficient for the specific purpose of the decommissioning study.

The second step leads to the programming of the NPP Monte Carlo model using the most current version of MCNP [1]. The model boundaries cover areas which contain all components and structures which - conservatively - could be activated above the free release limits at time of decommissioning.

In the next step, the Monte Carlo simulation is carried out and the neutron propagation from the reactor core through the reactor internals, the pressure vessel (RPV) and the different ducts and 


\section{$15^{\text {th }}$ ISRD}

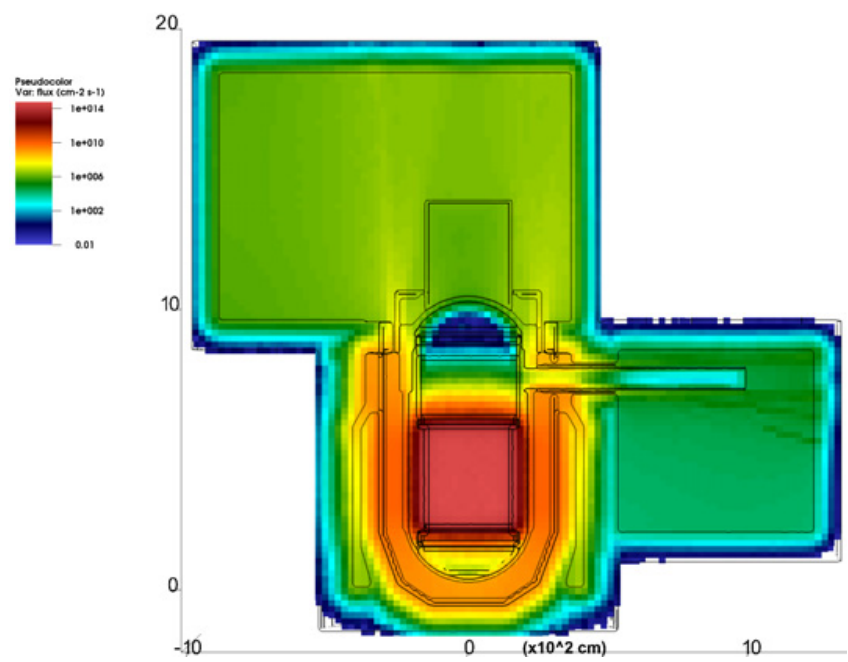

Figure 2. Neutron Flux Distribution for the PWR Gösgen.

streaming pathways outside the RPV into the surrounding structures and rooms is calculated. The neutron flux distribution is afterwards condensed into a number of NPP activation zones representing the "NPP activity atlas". This atlas serves for the optimization of the ensuing packaging concept and the development of the entire sequence of the decommissioning work itself.

Finally the validation of the methodology is performed by initiating an activation measurement campaign for one entire NPP operational cycle. Between 10 and 50 activation sets are placed within the plant at key locations. The activation of the sets - in general containing three different material foils, each covering specific neutron reactions for different neutron energy intervals - can be compared to the calculation results.

The methodology will be applied to the future Decommissioning Studies for all five Swiss NPPs scheduled for 2016. The first validation is already completed (PWR Gösgen (KKG)) and is presented in this paper. The validation efforts for the other Swiss NPPs are either under way or will soon be initiated.

\section{MCNP Simulations for the Swiss BWRs and PWRs}

To determine the activation inventory, state-of-the-art scientific and engineering methods are applied and lead to appropriate 3D Monte Carlo models for each of the Swiss NPPs. These NPP models aim at the calculation of the neutron flux distribution (see Fig. 2), its spectrum, reaction rates of key nuclides and resulting activity distributions within the relevant parts of the reactor building. The underlying transport problems include multiple streaming pathways.

For this reason, most advanced variance reduction (VR) methods [2] have been applied, since classical VR methods were found to reach their limits. Thus, validations of these results are strongly desired. Possible measurements of neutron dose rates for an NPP are limited by the accessibility of locations during its operation and even then deliver only limited information on the underlying neutron spectra. Much more meaningful is a neutron foil irradiation and measurement campaign with one full operational NPP cycle being used for the activation of the samples. To do this, Nagra has cooperated with professional experts for neutron metrology. 


\section{Neutron Metrology}

NRG (Nuclear Research \& consultancy Group) in Petten, The Netherlands, has been asked to determine the neutron fluence rate in three energy groups at different positions surrounding the drywell of the Mühleberg (KKM) and the Gösgen (KKG) NPP's.

The standard method applied by the neutron metrology group of NRG for this job is the application of neutron activation foils. Three types of activation foils have been selected to determine the neutron fluence rates; cobalt, silver and nickel. While cobalt and silver are sensitive to both thermal and intermediate energy neutrons, nickel is particularity sensitive to higher energy (fast) neutrons.

The foils were planned to be irradiated for an entire reactor cycle (about one year), and therefore only materials with long living activation products were the obvious choice. Because of the low fluence rates surrounding the drywell of an BWR or the pump room of an PWR, materials with large absorption cross-sections were chosen in order to avoid large amounts of material.

In total, 12 monitor sets (with activations foils) were prepared for PWR Gösgen, including 2 reserve sets. After irradiation, the foil sets were transported back to NRG for activation measurements and the determination of reaction and fluence rates.

\subsection{Activation Foil Sets}

Based on calculations made by NAGRA, estimations of the neutron fluence levels were made at the locations where the neutron activation sets would be mounted. Based on these estimations, the composition of the activation sets and the masses of the corresponding activation foils were determined in order to optimize gamma-spectrometric measurement times. Zones with higher thermal neutron fluences were equipped with Co-based and Ag-based alloy foils and zones with low or very low thermal neutron fluences were equipped with pure $\mathrm{Co}$ and $\mathrm{Ag}$ foils. In general the following activation foils were used:

- Co (or Co-based alloy) foil - for the determination of $\phi_{\text {th }}$ and $\phi_{\text {int }}$ using the reaction ${ }^{59} \mathrm{Co}(\mathrm{n}, \gamma){ }^{60} \mathrm{Co}$.

- $\mathrm{Ag}$ (or Ag-based alloy) foil - for the determination of $\phi_{\text {th }}$ and $\phi_{\text {int }}$ using the reaction ${ }^{109} \mathrm{Ag}(\mathrm{n}, \gamma){ }^{110 \mathrm{~m}} \mathrm{Ag}$.

- Ni foil - for the determination of $\phi_{\mathrm{f}}$ using the reaction ${ }^{58} \mathrm{Ni}(\mathrm{n}, \mathrm{p}){ }^{58} \mathrm{Co}$.

The sets with pure Co and Ag foils, which were employed at locations with lower thermal neutron fluences, suffer from neutron self-shielding and flux depression effects. Experimental self-shielding factors for each type of set have been determined in the Low Flux Reactor (LFR) at NRG, Petten. A general layout of such a set and a picture of the complete set is shown in Fig. 3.

\subsection{Tasks Carried out at NRG, Petten}

The following tasks have been carried out after receiving the irradiated activation sets at NRG:

- All the foils were unpacked from their corresponding set containers and the gamma particles emitted from the foils were measured using a 4096-channel HPGe detector coupled to a multichannel analyzer and an automatic sample changer.

- The activities of the nuclides were determined from the $\gamma$-spectra and corrected for gamma selfabsorption effects.

- The reaction rates at nominal reactor power for the reactions mentioned above were determined.

- Determination of the $2200 \mathrm{~m} \cdot \mathrm{s}^{-1}$ fluence rate based on the reaction rate and the $2200 \mathrm{~m} \cdot \mathrm{s}^{-1} \mathrm{cross}$ section of the reaction ${ }^{59} \mathrm{Co}(\mathrm{n}, \gamma){ }^{60} \mathrm{Co}$. 

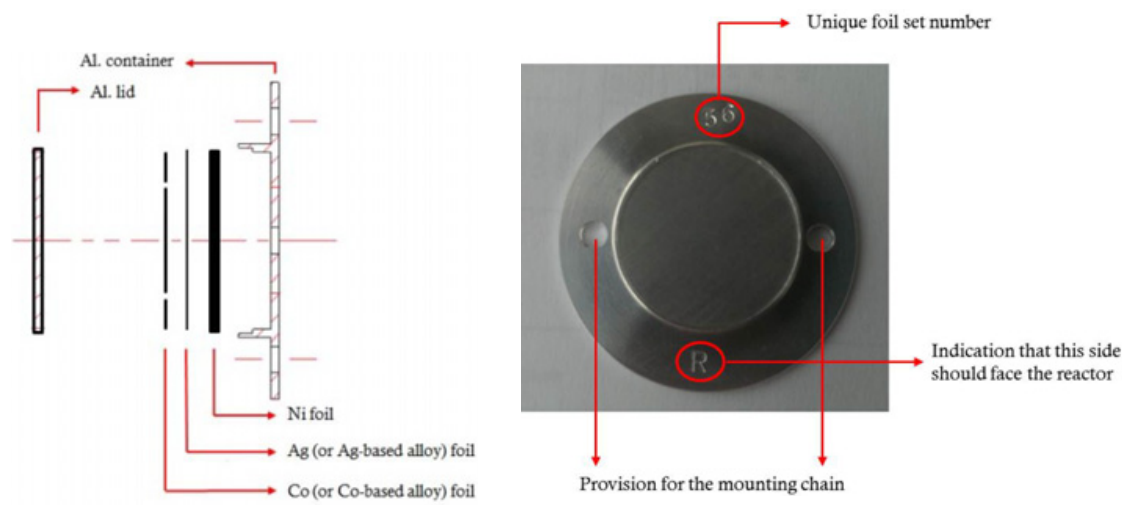

Figure 3. A general layout (left) and a picture (right) of an activation foil set used.

- Determination of the fast fluence rate based on the reaction rate and the fission spectrum averaged cross section of the reaction ${ }^{58} \mathrm{Ni}(\mathrm{n}, \mathrm{p}){ }^{58} \mathrm{Co}$.

- Determination of the thermal $(\mathrm{E}<0.5 \mathrm{eV})$ and the intermediate $(0.5 \mathrm{eV}<\mathrm{E}<1 \mathrm{MeV})$ fluence rates with the help of a proprietary code using the reactions ${ }^{59} \mathrm{Co}(\mathrm{n}, \gamma){ }^{60} \mathrm{Co}$ and ${ }^{109} \mathrm{Ag}(\mathrm{n}, \gamma){ }^{110 \mathrm{~m}} \mathrm{Ag}$.

- All the results mentioned above were accompanied by their corresponding $2 \sigma$ uncertainties [3].

\section{Monitor Set Placement at Key Positions within the PWR Gösgen}

Figure 4 shows a cross section of the MCNP model for the PWR of Gösgen (KKG) including the chosen locations of most of the neutron activation sets (or "samples").

For the placement of the monitor sets inside the reactor building two aspects are most important:

(1) a well-considered choice of key positions with regard to the validation purpose of the Monte Carlo simulation and

(2) the accurate documentation of each set's position since - for those sets within a strong neutron flux gradient - a displacement of only a few centimeters can be significantly change the activation level.

The sets have been placed inside the gap between the RPV head and the reactor pit leading to the basin area above ( 4 samples), in the basin area itself ( 2 samples) and finally in one of the adjacent pump rooms (4 samples). All sets are at representative key locations characterizing either the streaming effects of neutrons within these gaps or the neutron radiation field within the respective part of the room or area. Figure 5 shows a picture of two of the four sets inside the KKG RPV head gap (coin shaped Al-box attached to an Al-chain).

After being irradiated for one entire reactor cycle (i.e. approx. 1 year), the monitor sets are retrieved from the KKG reactor and sent to NRG for the analysis of each foil's activity.

Figure 6 shows a cross section of the KKG MCNP model demonstrating the neutron streaming behaviour alongside the main cooling pipe penetration through the biological shield into the pump room. A strong gradient of the neutron radiation field in this room can be seen, leading to significantly different specific foil activation levels within this room: sample \#9 will be much less activated compared to one of the samples directly in front of the cooling pipe exit gap. 
EPJ Web of Conferences

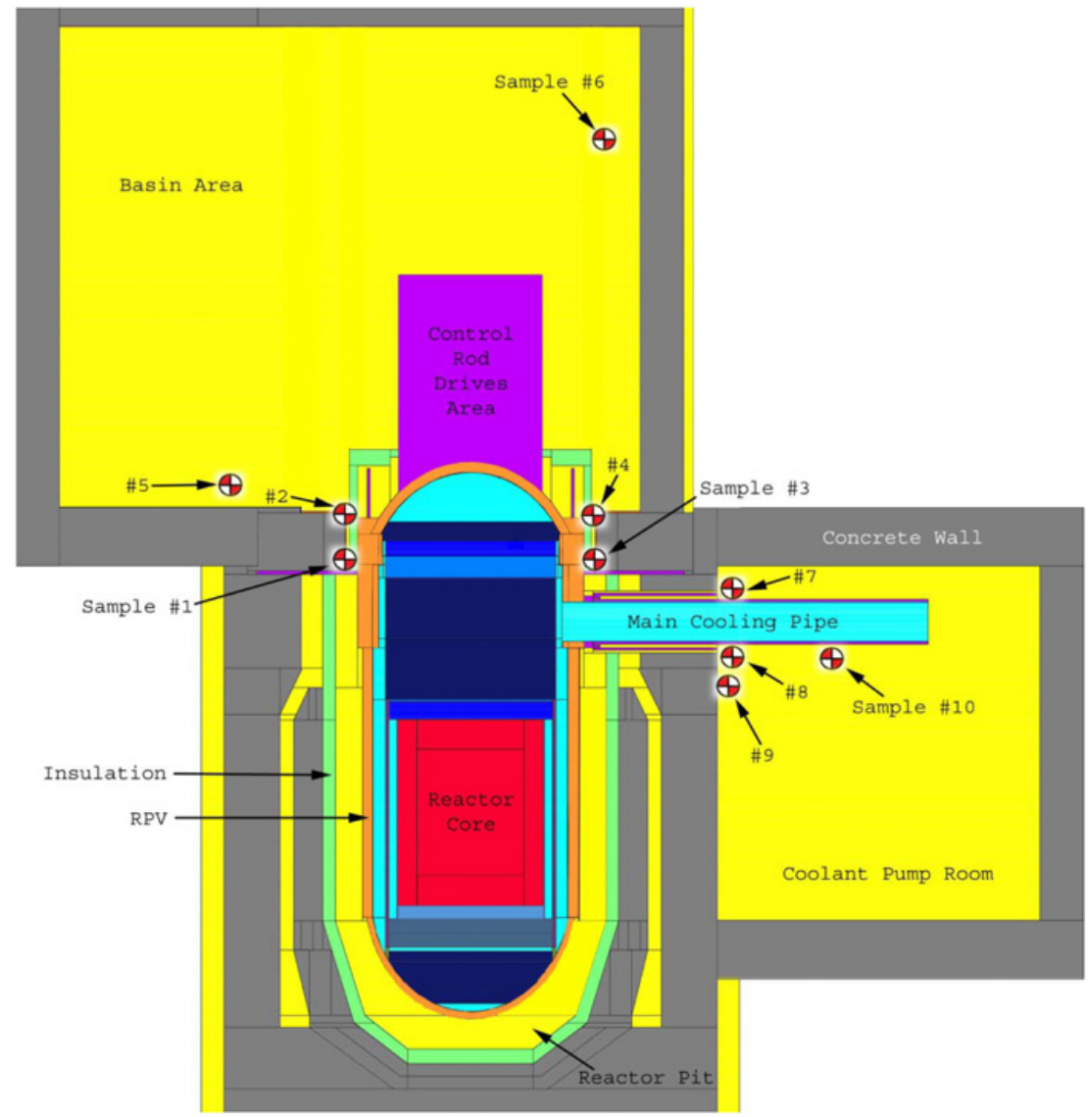

Figure 4. Locations of the $10 \mathrm{KKG}$ neutron activation monitor sets ("Sample \#x").

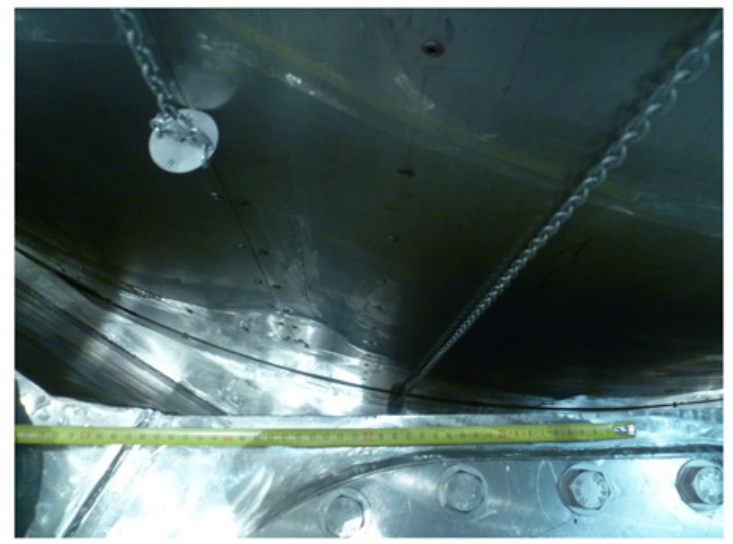

Figure 5. Two sets within the RPV-bioshield-gap of KKG. 


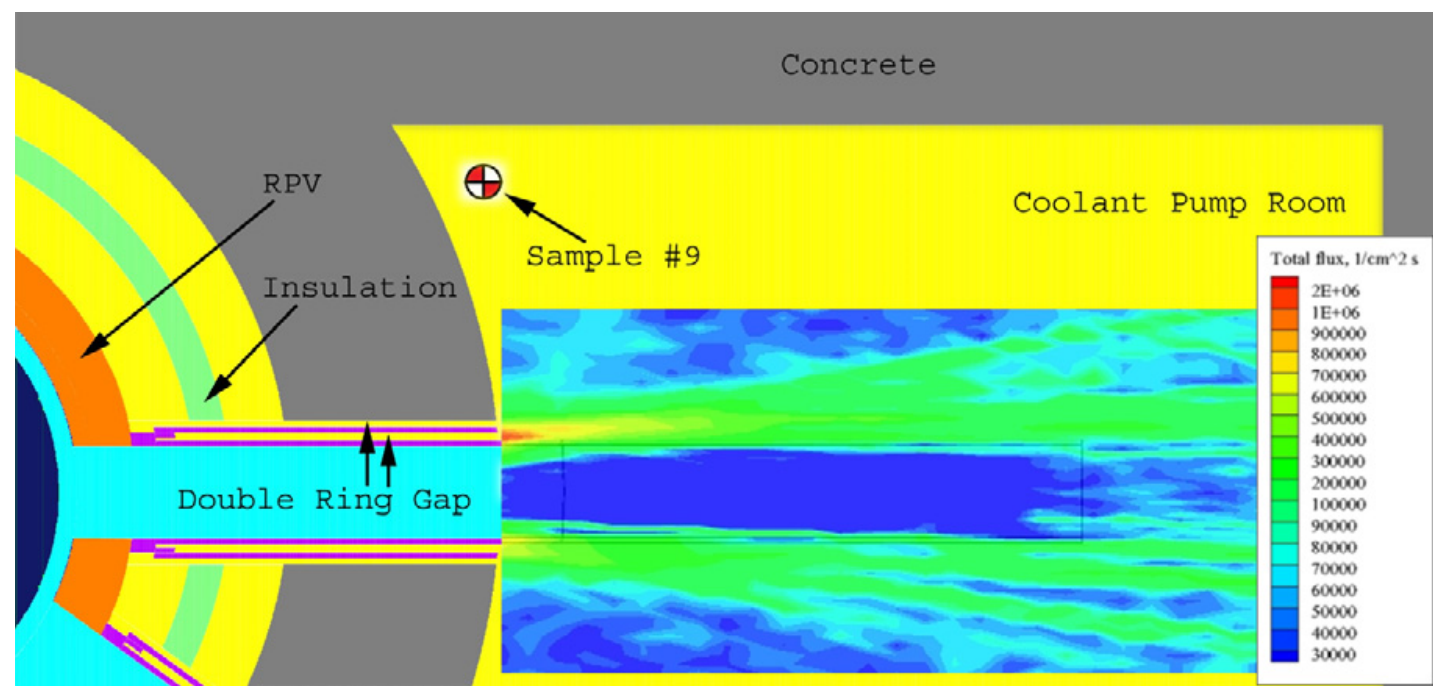

Figure 6. Neutron streaming characteristic alongside the main cooling pipe into the pump room of KKG.

Table 1. Comparison of calculated-to-measured (Calc/Meas) activities for neutron activation sets \#1-10.

\begin{tabular}{|c|c|c|c|c|c|c|}
\hline $\begin{array}{c}\text { Sample } \\
\#\end{array}$ & $\begin{array}{l}\text { A(Co-60) } \\
\text { Calc/Meas }\end{array}$ & $\begin{array}{l}\text { A(Ag- } 110 \mathrm{~m}) \\
\text { Calc/Meas }\end{array}$ & $\begin{array}{l}\text { A(Co-58) } \\
\text { Calc/Meas }\end{array}$ & $\begin{array}{c}\text { Total Flux } \\
\left(\mathrm{n} / \mathrm{cm}^{2}\right)\end{array}$ & $\begin{array}{c}\text { Relative } \\
\text { Error of } \\
\text { Total Flux }\end{array}$ & Description of Sample Locations \\
\hline 1 & 0.9 & 1.4 & 1.1 & 2.3E8 & $0.2 \%$ & Reactor Basin / RPV Ring Gap [-1 m, near Cooling Pipe YA10] \\
\hline 2 & 1.4 & 1.9 & 1.5 & 2.7E7 & $0.9 \%$ & Reactor Basin / RPV Ring Gap [ $0 \mathrm{~m}$, near Cooling Pipe YA10] \\
\hline 3 & 1.1 & 1.5 & 1.2 & 2.1E8 & $0.2 \%$ & Reactor Basin/ RPV Ring Gap [-1 m, near Cooling Pipe YA20] \\
\hline 4 & 2.1 & 2.8 & 2.1 & 2.7E7 & $1.0 \%$ & Reactor Basin/ RPV Ring Gap [ $0 \mathrm{~m}$, near Cooling Pipe YA20] \\
\hline 5 & 1.4 & 3.1 & 1.9 & $1.0 \mathrm{E} 6$ & $5.7 \%$ & Reactor Basin Area, Ground Level \\
\hline 6 & 1.8 & 3.4 & 2.6 & $2.0 \mathrm{E} 6$ & $3.3 \%$ & Reactor Basin Area, +7 m above Floor Level \\
\hline 7 & 2.7 & 2.8 & 3.1 & $2.6 \mathrm{E} 5$ & $5.6 \%$ & Cooling Pipe Exit into Pump Room, on Top of Pipe \\
\hline 8 & 3.5 & 3.9 & 2.5 & 4.9E5 & $7.6 \%$ & Cooling Pipe Exit into Pump Room, near Bottom of Pipe \\
\hline 9 & 3.8 & -- & -- & 1.1E4 & $6.3 \%$ & Pump Room, inner Wall, near Access Door to Reactor Pit \\
\hline 10 & 3.4 & -- & 1.5 & $2.2 \mathrm{E} 5$ & $13 \%$ & Along Bottom of Cooling Pipe, $2.5 \mathrm{~m}$ from Pump Room inner Wall \\
\hline
\end{tabular}

\section{Comparison of Calculations with Measurements for KKG}

The comparison of the NPP Monte Carlo calculations with the results of the NPP neutron foil activation campaigns is done by using a stand-alone generic MCNP model functioning as an interface and allowing the simulation of individual foil activation by predetermined neutron spectra originating from the NPP MCNP calculations.

The comparison between calculations and measurements for the 10 monitor sets of the PWR Gösgen (KKG) show - except for one single foil - a general overestimation of the induced activities for all foils between a factor of 0.9 and 3.9 (see Table 1). The key nuclide for the decommission planning (i.e. Co-60) 
is determined even more reliably - except for the locations within the pump room. Here a certain lack of knowledge of the existing boundary conditions - concerning the cooling pipe isolation material as well as the cooling pipe gap dimensions - impedes the calculations. Nevertheless, the resulting activation mapping (i.e. activity atlas) for the NPP Gösgen is already sufficiently accurate and - at the same time conservative - to develop a packaging concept for the ensuing decommission planning and cost estimation steps.

A similar validation effort for the BWR Mühleberg (KKM) is expected to be finalized by the end of 2014. The neutron foil irradiation campaigns for PWR Beznau and BWR Leibstadt are scheduled to be initialized in 2014/2015. Meanwhile the Nagra methodology is also being applied for decommission planning for a BWR in southern Germany: in May 2014 more than 50 monitor sets have been placed inside the reactor unit B of NPP Gundremmingen which is scheduled to shut down at the end of 2017.

To summarize, the comparison between calculations and measurements for the neutron activation monitor sets serve as a sound validation of the Nagra NPP activation methodology by demonstrating a satisfying agreement with regard to its purpose: NPP decommission planning.

\section{References}

[1] X-5 Monte Carlo Team, MCNP - A General Monte Carlo N-Particle Transport Code, Vers. 5, LA-UR-03-1987, Los Alamos National Lab (2003, revised 2008)

[2] M. Pantelias, S.W. Mosher, Monte Carlo, Hybrid and Deterministic Calculations for the Activation Neutronics of Swiss LWRs, Trans. Am. Nucl. Soc., 109 (2013)

[3] B. Straathof, Neutron fluence rate determinations in Mühleberg and Gösgen Nuclear Power Plants, NRG Report 22967/119647 rev. nr. D, Petten (April 2013) 